Folia phoniat. 1959;11:1-4

\title{
In memoriam Dr. Heinz Karger
}

I in Alter von 63 Jahren ist Dr. h.c. Heinz Karger, Basel, am27.März 1959 unerwartet rasch gestorben. Er durchlief seine Lehrjahre in der akademischen Buchhandlung Haller und Schmidt in Berlin. Schon damals zeichnete er sich durch einen großen Wissensdurst und einen zähen Willen aus, möglichst rasch alle Einzelheiten eines großen buchhändlerischen Betriebes kennen zu lernen. Um jene Zeit begann der erste Weltkrieg, den er mitmachte. Als die Machtansprüche des Dritten Reiches urns Jahr 1935 immer größer wurden, faßte Dr. Heinz Karger mit seinem Bruder den tapferen Entschluß, ihren bekannten medizinischen Verlag nach Basel zu verlegen. Es war keine leichte Sache, diesen auf eine ganz neue, Internationale Grundlage zu stellen, und durch den zweiten Weltkrieg bedingt, mußte der Verlag S. Karger in Basel unter großen Opfern recht bescheiden durchgehalten werden. Dr. Heinz Karger durfte anläßlich seines 60 .

Geburtstages bewegte Zuschriften seiner dankbaren engeren Mitarbeiter und der zahlreichen Redaktoren entgegennehmen, woraus hervorging, wie wichtig es war, in der Schweiz während der zunehmenden Abriegelung gegen außen - besonders im Bereich der Spezialgesellschaften die wissenschaft-lichen Arbeiten in unserem Land als schweizerischen Ursprungs zu dokumentieren.

Dr. Heinz Karger genoß im In- und Ausland hohes Ansehen. 1955 verlieh ihm die hohe medizinische Fakultät Basel in Anerkennung seiner Verdienste um die verlegerische Tätigkeit auf medizinischem Gebiet den Doktortitel h.c. Dem Verleger stand der Mensch nicht nach. Er zeichnete sich durch Festigkeit des Charakters, Klarheit des Geistes, ruhige Besonnenheit im Urteil und spürbare menschliche Wärme aus.

Als ich 1946 nach einer Aussprache mit meinem französischen Freund Dr. Jean Tarneaud an den Chef des Karger-Verlages mit der Frage der Herausgabe einer internationalen medizinischpädagogi-schen Zeitscbrift auf dem Spezialgebiet der Logopädie und Phoniatrie herantrat, setzte er sich sogleich großzügig und wagemutig für das Unternehmen ein. Während der schwierigen Anfangszeit erlahmte sein Optimismus nie. Er wußte wertvolle Internationale Verbindungen zwischen den Forschern und Praktikern zu schaffen.

So gedenken heute die Redaktoren, die Mitherausgeber und die zahlreichen Leser der «Folia phoníatríca» seines mutigen und weit-blickenden Einsatzes, und sie werden den allzu früh Verblichenen stets in ehrender Erinnerung behalten. Wir wissen, daß sein Tod eine große Lücke im Verlag Karger gerissen hat; doch dürfen wir voiles Vertrauen haben, daß sein Sohn Thomas, unterstützt von seinem Onkel und bewährten Mitarbeitern, das Werk seines Vaters tatkräftig und großzügig weiterführen wird. Ich rufe nochmals die schicksalshaften Worte von Hermann Hesse ins Gedächtnis, die ein Gratulant Dr. Heinz Karger vor 4 Jahren niederschrieb: «Es muß das Herz bei jedem Lebensrufe - Bereit zum Abschied sein und Neu-beginne - Um sich in Tapferkeit und ohne Trauern - In neue, andere Bindungen zu geben». 


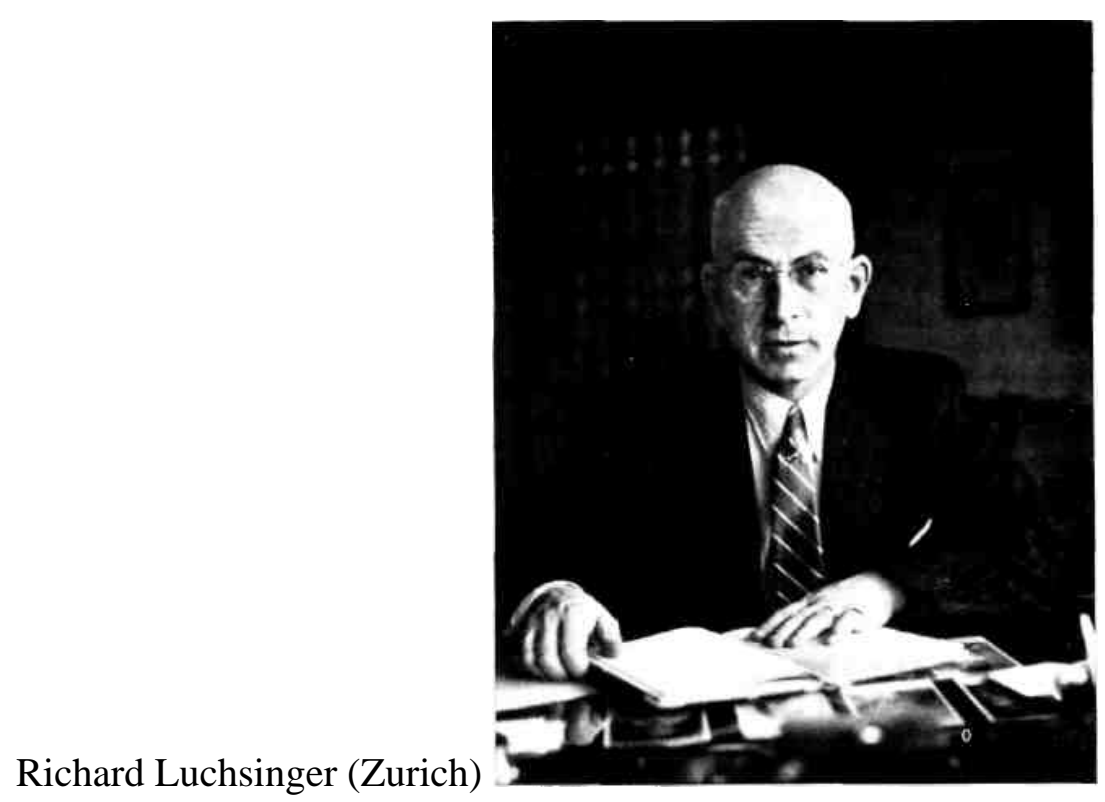

